\title{
Дренажные растворы зоны выщелачивания гипергенного профиля метабазальтов. Зависимость состава дренажных растворов от уровня метаморфизма субстрата
}

\author{
Климова Е.В. ${ }^{1}$, Матреничев В.А. ${ }^{2}$ \\ ${ }^{1}$ Институт геологии и геохронологии докембрия РАH, Санкт-Петербург, katya_kli@list.ru \\ ${ }^{2}$ Санкт-Петербургский горный университет, Санкт-Петербург, ppbaт@yandex.ru
}

Аннотация. Изучение кор выветривания имеет большой теоретический и практический интерес, поскольку они играют огромную роль в формировании осадочной оболочки Земли и служат источником уникальной информации о составе и закономерностях эволюционных изменений литосферы, атмосферы и гидросферы. С целью моделирования перераспределения элементного состава при формировании гипергенных профилей раннего докембрия был проведен ряд экспериментов по взаимодействию палеопротерозойских основных пород с растворами различной кислотности. Для экспериментов были использованы образцы метавулканитов основного состава (оз. Суйсарь) и амфиболитов (метабазальтов) (оз. Янисьярви). Результаты экспериментов свидетельствуют о том, что максимальные концентрации катионов в дренажных растворах формируются в кислотных условиях после выщелачивания слабо метаморфизованных метавулканитов. В этих условиях суммарная концентрация катионов варьирует от 10 мг/л до 26 мг/л. Повышенная минерализация в этих растворах достигается за счет высоких концентраций Са и $\mathrm{Mg}$, тогда как остальные компоненты растворов почти не различаются. Наиболее вероятно, что особенности катионного состава растворов обусловлены различием минерального состава субстрата. Для метавулканитов характерно высокое содержание хлорита, до $25 \%$, тогда как в амфиболитах резко преобладает амфибол. Отношение $\mathrm{Rb} / \mathrm{Sr}$ в растворах при выщелачивании метавулканитов, в минеральном составе которых содержится до 25 \% хлорита, выше чем отношение $\mathrm{Rb} / \mathrm{Sr}$ при выщелачивании амфиболитов. Отношение $\mathrm{K} / \mathrm{Na}$ в экспериментальных дренажных растворах устойчиво ниже единицы.

Ключевые слова: докембрий, кора выветривания, эксперименты.

\section{The dependence of the composition of drainage solutions in the weathering crust of metabasalts on the degree of their metamorphic transformation}

\author{
Klimova E.V. ${ }^{1}$, Matrenichev V.A. ${ }^{2}$ \\ ${ }^{1}$ Institute of Precambrian geology and geochronology Russian Academy of Sciences, St. Petersburg, \\ katya_kli@list.ru \\ ${ }_{2}^{2}$ Saint Petersburg Mining University, St. Petersburg,ppbam@yandex.ru
}

\begin{abstract}
The study of weathering crusts is of great theoretical and practical interest, as they serve as a source of information about the composition and patterns of evolutionary changes in the lithosphere, atmosphere, and hydrosphere. To modeling the redistribution of the elemental composition during weathering crust formation in the early Precambrian, experiments on the interaction of basic rocks with solutions of different acidity were conducted. Paleoproterozoic basic rocks from Karelia, including weakly metamorphosed volcanic rocks (lake Suisar) and amphibolites (metabasalts) (lake Yanisyarvi), were used as starting material for the experiments. The experimental results indicate maximal cation concentrations in drainage solution form under acidic conditions during leaching of the weakly metamorphosed volcanic rocks. Under these conditions, the total concentration of cations varies from $10 \mathrm{mg} / \mathrm{l}$ to $26 \mathrm{mg} / \mathrm{l}$. Increased mineralization in these solutions is based on the high concentrations of $\mathrm{Ca}$ and $\mathrm{Mg}$; the other cation components are almost indistinguishable in solutions resulted from different conditions. Various cationic compositions of the drainage solutions are likely based on the mineral composition of the used starting material. The metavolcanic rocks are characterized by a high chlorite content, up to $25 \%$, while amphibolites are dominated by amphibole. The $\mathrm{Rb} / \mathrm{Sr}$ ratio in solutions for leaching the metavolcanic rocks is higher than that for the amphibolites. The $\mathrm{K} / \mathrm{Na}$ ratio in experimental solutions is consistently below the unity.
\end{abstract}

Key words: Precambrian, weathering crust, experiments. 


\section{Введение}

Интерес к дренажным растворам в связи с проблемой выветривания горных пород и формирования коры выветривания начался с изучения подвижности химических элементов и стадийности выщелачивания последних из алюмосиликатных горных пород. С системой вода-порода связаны многочисленные и крайне важные геологические процессы: мобилизация, перенос, рассеивание и концентрирование химических элементов в разных геохимических средах; транспортировка вещества, его отложение в бассейнах седиментации. Изучение кор выветривания имеет большой теоретический и практический интерес, поскольку они играют огромную роль в формировании осадочной оболочки Земли и служат источником уникальной информации о составе и закономерностях эволюционных изменений литосферы, атмосферы и гидросферы.

Докембрийские коры выветривания, как правило, метаморфизованы, поэтому выявление и изучение таких кор намного сложнее, чем изучение неизмененных кор более молодого возраста, тем не менее, это единственный геологический объект, возникающий в результате взаимодействия литосферы, атмосферы, гидросферы и биосферы и позволяющий реконструировать особенности этих оболочек на разных стадиях эволюции Земли.

Целью работы было моделирование перераспределения маркерных элементов при формировании гипергенных профилей раннего докембрия на материале экспериментального исследования взаимодействия пород с растворами различной кислотности.

\section{объекты и методы}

Для экспериментов по мобилизации вещества были использованы образцы людиковийских метавулканитов основного состава суйсарской свиты Онежской структуры (о. Суйсарь) и амфиболиты (метабазальты) соанлахтинской свиты Янисъярвинской структуры.

Метавулканиты Онежской структуры представлены массивными пироксен-плагиоклазовыми порфиритами. В их минеральном составе выделяются порфировые вкрапленники авгита ( 20 об. \%) и плагиоклаза ( 41 об. \%). В основной массе преобладает хлорит ( 25 об. \%), отмечаются реликты микролитов плагиоклаза, а также в незначительном количестве встречается микроклин и сфен (Матреничев А.В. и др., 2010).

Метабазальты соанлахтинской свиты обнажаются на северном берегу оз М. Янисъярви. Породы представлены серо-зелеными амфиболитами с реликтами подушечной отдельности. Межподушечное пространство выполнено высококремнистым материалом. Большая часть породы замещена сине-зелёной роговой обманкой. Иногда в шлифе встречаются реликты порфировых вкрапленников плагиоклаза (Матреничев А.В. и др., 2010).

Образцы пород были предварительно раздроблены в механической дробилке, затем разделены по фракциям ситованием. Для экспериментов использовалась фракция размером от 0.25-0.5мм. Образец помещался в кислый и щелочной растворы ( $\mathrm{pH}-3$ и $\mathrm{pH}-10)$. Для приготовления растворов использовались дистиллированная вода, серная кислота (ЧДА) для раствора с $\mathrm{pH}=3$ и аммиак (ЧДА) для раствора с $\mathrm{pH}=10$. Диапазон вариаций $\mathrm{pH}$ включает большую часть доступных сейчас кислотных обстановок в области гипергенных преобразований, от щелочных условий кристаллизации карбонатов в корах выветривания (Матреничев и др., 2011) до ультракислых в областях современного вулканизма и антропогенного воздействия (Израэль и др., 1989).

Эксперименты проводились в кислородных условиях, время взаимодействия раствора с породой составляло 1 час, 1 сутки, 1 неделя. Время взаимодействия породы и раствора в опыте моделирует различия условий дренажа гипергенного профиля таким образом, что короткое время взаимодействия отражает условия высокой влажности и интенсивной фильтрации растворов, тогда как длительные эксперименты характеризуют застойные зоны гипергенного профиля и в целом засушливые условия.

После взаимодействия с породой растворы были отфильтрованы. Катионный состав растворов до и после взаимодействия определялся методом масс-спектрометрии с индуктивно связанной плазмой в центральной аналитической лаборатории ВСЕГЕИ. $\mathrm{pH}$ исходных и экспериментальных 
растворов определен pH-метром InoLab. Относительная погрешность измерения составляет не более $5 \%$. Эксперименты различной длительности были установлены таким образом, чтобы они завершились одновременно и полученные растворы были проанализированы в одной серии.

\section{Результаты исследования}

Результаты экспериментального исследования перераспределения элементов между горными породами и водными растворами различной кислотности приведены в табл. 1.

Эксперименты по выщелачиванию метавулканитов оз. Суйсарь в кислых условиях. При выщелачивании вулканитов в кислой среде, сумма катионов экспериментальных растворов постепенно увеличивается от 16 мг/л при коротких экспериментах до 26 мг/л при экспериментах длительностью 7 суток. Суммарная концентрация лантаноидов в кислой среде постепенно уменьшается от 1.5 мкг/л, при коротких экспериментах до 0.2 мкг/л при времени взаимодействия 7 суток (табл. 1). Концентрация La при времени проведения эксперимента от 1 часа до 7 суток уменьшается от 0.3 мкг/л до 0.02 мкг/л. Отношение $\mathrm{La} / \mathrm{Yb}$ в зависимости от времени взаимодействия раствор-порода уменьшается от 17 при времени взаимодействия 1 час до 9 для 7 суток.

Эксперименты по выщелачиванию метавулканитов оз. Суйсарь в щелочных условиях. В растворах при $\mathrm{pH}=10$ сумма катионов увеличивается от 5 мг/л при коротких экспериментах до 10 при длительных экспериментах (табл. 1). В окислительных условиях при $\mathrm{pH}=10$ суммарная концентрация РЗЭ почти не изменяется в зависимости от времени проведения эксперимента. Отношение $\mathrm{La} / \mathrm{Yb}$ уменьшается от 7 при коротких экспериментах до 4 при длительных экспериментах.

Эксперименты по выщелачиванию амфиболитов оз. Янисъярви в кислых условиях. Сумма катионов при $\mathrm{pH}=3$ при выщелачивании амфиболитов уменьшается от 11 мг/л до 8 мг/л (табл. 1). Суммарная концентрация лантаноидов в кислой среде постепенно увеличивается от 0.05 мкг/л, при коротких экспериментах до 0.1 мкг/л при времени взаимодействия 7 суток (табл. 1). Концентрация $\mathrm{La}$ не изменяется в зависимости от времени проведения эксперимента и составляет 0.01 мкг/л. Отношение $\mathrm{La} / \mathrm{Yb}$ в зависимости от времени взаимодействия раствор-порода изменяется от 3 при времени взаимодействия 1 час до 6 за сутки и затем уменьшается до 4 при времени экспозиции 7 суток.

Эксперименты по выщелачиванию амфиболитов оз. Янисъярви в щелочных условиях. В щелочных растворах сумма катионов уменьшается от 8мг/л до 6 мг/л (табл. 1). Суммарная концентрация РЗЭ уменьшается незначительно при времени взаимодействия от 1 суток до 7 суток от 0.05 до 0.02 мкг/л. Отношение $\mathrm{La} / \mathrm{Yb}$ почти не изменяется и равно 2.

\section{Обсуждение результатов}

Результаты экспериментов по выщелачиванию метабазальтов и амфиболитов свидетельствуют о том, что максимальные концентрации катионов в дренажных растворах формируются в кислотных условиях после выщелачивания слабо метаморфизованных метавулканитов. В этих условиях суммарная концентрация катионов варьирует от 10 мг/л до 26 мг/л. Повышенная минерализация в этих растворах достигается за счет высоких концентраций Са и $\mathrm{Mg}$, тогда как остальные компоненты растворов почти не различаются. Наиболее вероятно, что особенности катионного состава растворов обусловлены различием минерального состава субстрата. Для метавулканитов характерно высокое содержание хлорита, до 25 \%, тогда как в амфиболитах резко преобладает амфибол.

По мере увеличения времени взаимодействия породы и раствора происходит уменьшение $\mathrm{La} / \mathrm{Yb}_{\mathrm{N}}$ отношения.

$\mathrm{B}$ экспериментальных растворах наибольшие различия наблюдаются для концентраций Rb и $\mathrm{Sr}$ в зависимости от условий эксперимента и от образца, используемого в эксперименте (табл. 1). Концентрация $\mathrm{Sr}$ при выщелачивании амфиболитов Янисъярви в кислых и щелочных растворах не изменяется в зависимости от времени выщелачивания и составляет 0.04 мг/л и 0.01 мг/л соответственно. Концентрация Rb в кислых растворах не изменялась в зависимости от времени выщелачивания амфиболитов Янисъярви, её значение 0.002 мг/л. Концентрация Rb в щелочных растворах изменилась на порядок. Концентрация $\mathrm{Rb}$ при коротком времени выщелачивания амфиболитов оз. Янисьярви равна 0.02 мг/л и уменьшилась до 0.001 мг/л при длительных экспериментах. 
Концентрация $\mathrm{Sr}$ почти не изменялась в растворах при выщелачивании кислыми растворами метавулканитов о. Суйсарь (0.01 мг/л). А в щелочных растворах увеличилась на порядок, от 0.0006 мг/л в коротких экспериментах до 0.002 мг/л в длительных экспериментах. Концентрация Rb в кислых и щелочных экспериментах изменялась незначительно от 0.001 мг/л при коротких экспериментах до 0.007 мг/л в длительных экспериментах.

Отношение $\mathrm{K} / \mathrm{Na}$ в полученных растворах не зависит от времени и условий проведения эксперимента и устойчиво ниже единицы, составляя в среднем 0.6.

Таким образом, основными результатами экспериментального исследования мобилизации вещества при взаимодействии кислотных и щелочных растворов с основными породами являются выводы о том, что:

(1) Растворы с наибольшей минерализацией наблюдаются при выщелачивании кислым раствором слабо метаморфизованных вулканитов, в минеральном составе которых содержится до $25 \%$ хлорита. Максимальная суммарная концентрация катионов в этих растворах связана с повышенной концентрацией Са и $\mathrm{Mg}$, тогда как остальные компоненты растворов почти не различаются.

(2) Отношение $\mathrm{Rb} / \mathrm{Sr}$ в растворах при выщелачивании метавулканитов, в минеральном составе которых содержится до 25 \% хлорита, выше чем отношение $\mathrm{Rb} / \mathrm{Sr}$ при выщелачивании амфиболитов.

(3) Отношение $\mathrm{K} / \mathrm{Na}$ в экспериментальных дренажных растворах устойчиво ниже единицы.

Таблица 1. Состав экспериментальных растворов.

Table 1. Composition of experimental solutions.

\begin{tabular}{|c|c|c|c|c|c|c|c|c|c|}
\hline $\mathrm{t}$, сут & Кат $^{+}$ & Р3Э & $\mathrm{La} / \mathrm{Yb}_{\mathrm{N}}$ & $\mathrm{K} / \mathrm{Na}$ & $\mathrm{Ca} / \mathrm{Na}$ & $\mathrm{Ca}$ & $\mathrm{Mg}$ & $\mathrm{Rb} / \mathrm{Sr}$ \\
\hline \multicolumn{8}{|c|}{ Метавулканиты о3. Суйсарь, $\mathrm{pH}=3$} \\
\hline 0.042 & 16 & 1.55 & 17 & 0.6 & 2.3 & 5.9 & 3.4 & 0.14 \\
\hline 1 & 24 & 0.19 & 16 & 0.6 & 2.0 & 8.4 & 6.6 & 0.19 \\
\hline 7 & 26 & 0.12 & 9 & 0.7 & 2.1 & 9.5 & 7.2 & 0.31 \\
\hline \multicolumn{8}{|c|}{ Метавулканиты оз. Суйсарь, $\mathrm{pH}=10$} \\
\hline 0.042 & 5 & 0.16 & 7 & 0.7 & 0.2 & 0.3 & 0.3 & 2.49 \\
\hline 1 & 7 & 0.12 & 3 & 0.6 & 0.2 & 0.4 & 0.3 & 4.16 \\
\hline 7 & 10 & 0.11 & 4 & 0.7 & 0.2 & 0.9 & 0.5 & 2.80 \\
\hline \multicolumn{8}{|c|}{ Амфиболиты оз. Янисьярви, $\mathrm{pH}=3$} \\
\hline 0.042 & 11 & 0.05 & 3.5 & 0.6 & 0.4 & 1.7 & 2.3 & 0.04 \\
\hline 1 & 10 & 0.14 & 5.7 & 0.8 & 0.6 & 1.8 & 2.6 & 0.04 \\
\hline 7 & 8 & 0.07 & 3.9 & 0.7 & 0.7 & 1.4 & 2.1 & 0.04 \\
\hline \multicolumn{8}{|c|}{ Амфиболиты оз. Янисъярви, pH=10 } \\
\hline 0.042 & 8 & 0.05 & 2.3 & 0.8 & 0.1 & 0.4 & 0.7 & 1.73 \\
\hline 1 & 6 & 0.03 & 2.1 & 0.8 & 0.2 & 0.4 & 0.6 & 0.12 \\
\hline 7 & 6 & 0.02 & 1.9 & 0.6 & 0.2 & 0.5 & 0.7 & 0.08 \\
\hline
\end{tabular}

Примечание: $\mathrm{KaT}^{+}$- суммарная концентрация катионов, мг/л; РЗЭ - суммарная концентрация лантаноидов, мкг/л.

Работа выполнена в рамках темы НИР № FMNU-2019-0001.

\section{Литература}

1. Израэль Ю.А., Назаров И.М., Прессман А.Я., Филиппова Л.М., Рябошапко А.Г. Кислотные дожди. Л. Изд-во: Гидрометеоиздат. 1989. 269 с.

2. Матреничев А.В., Матреничев В.А., 2010, Петрология людиковийского вулканизма Онежской структуры и Раахе-Ладожской зоны. Балтийский щит // Сборник трудов молодых ученых ИГГД РАН. СПб. Изд-во: Политехн. ун-та. 2010. С. 223-255.

3. Матреничев В.А., Алфимова Н.А., Левченков О.А. и др. Стратиграфия и изотопный возраст лопийского комплекса Лехтинской структуры, северная Карелия // Стратиграфия, геологическая корреляция, 2011. T. 19. № 5. С. 3-25. 